\title{
Platelet activation during exercise induced asthma: effect of prophylaxis with cromoglycate and salbutamol
}

\author{
CE JOHNSON, PW BELFIELD, S DAVIS, NJ COOKE A SPENCER, JA DAVIES
}

From the Department of Respiratory Medicine and University Department of Medicine, General Infirmary, Leeds

ABSTRACT Peak expiratory flow (PEF) and plasma concentrations of platelet factor 4 and $\beta$ throm-i boglobulin were measured before and after exercise in nine asthmatic patients and 12 non-asthmatic ${ }^{\circ}$ volunteers. Exercise was preceded by administration in random order of either placebo, salbutamolo $200 \mu \mathrm{g}$, or sodium cromoglycate $2 \mathrm{mg}$ from a pressurised inhaler. In control subjects there were minimal changes in PEF and plasma concentrations of platelet factor 4 and $\beta$ thromboglobulin. In the asthmatic patients the typical changes in PEF were seen on exercise; plasma concentrations of platelet factor 4 and $\beta$ thromboglobulin rose significantly in parallel, the rise preceding the fall in $\oplus_{\odot}$ PEF. The changes in peak flow and platelet activation induced by excercise were attenuated by prior ${ }^{\circ}$ administration of salbutamol or cromoglycate. These results indicate that exercise induced asthma is associated with a rise in platelet release products similar to that observed in antigen induced asthma.

There is considerable evidence that inflammatory mediators are the underlying agents of bronchoconstriction in asthma. ${ }^{1}$ Several of these substances, and particularly platelet activating factor (PAFacether), also cause activation of blood platelets. This has been detected during antigen induced asthma by measurement of platelet factor $4,{ }^{2} \beta$ thromboglobulin, ${ }^{3}$ and change in the platelet aggregate ratio. ${ }^{3}$ These findings have been interpreted to indicate that antigen induced asthma is accompanied by sensitisation of mast cells and release of chemical mediators. While there is general support for the idea that this pathway is concerned in antigen induced asthma, there is controversy about the role of mediators in exercise induced asthma. ${ }^{4-7}$ We have therefore assessed platelet activation during exercise in asthmatic patients known to be susceptible to exercise induced asthma by measuring platelet factor 4 and $\beta$ thromboglobulin. The results obtained in these subjects were compared with findings in non-asthmatic subjects undergoing similar exercise. On separate occa-

Address for reprint requests: Dr PW Belfield, Department of Respiratory Medicine, General Infirmary, Leeds LSI 3EX.

Accepted 24 September 1985 sions the platelet release response to exercise waş measured in the asthmatic subjects after adminis tration of sodium cromoglycate and salbutamol drugs known to modify exercise induced asthma. ${ }^{8}$

\section{Methods}

We studied nine asthmatic subjects attending the out patient clinic (mean age 23 years) and 12 non asthmatic members of the medical and laborator staff (mean age 31 years). The details of the asthmatio patients are shown in the table. All subjects gave ful informed consent to take part and the study was apo proved by the Leeds Western District research ethics committee. Both patients and control subjects discono tinued all medication on the evening before eactg study day.

Exercise was carried out on a treadmill at room temperature (about $20^{\circ} \mathrm{C}$ ) and all of the participants had experienced the procedure at least once before the study. The speed and elevation of the treadmill weriet adjusted for each individual so that six minutes of sustained submaximal exercise could be carried out The chosen work load raised the mean pulse rate t $\vec{S}$ 152 beats per min in the asthmatic subjects and 148 beats per min in the controls. Control subjects were 


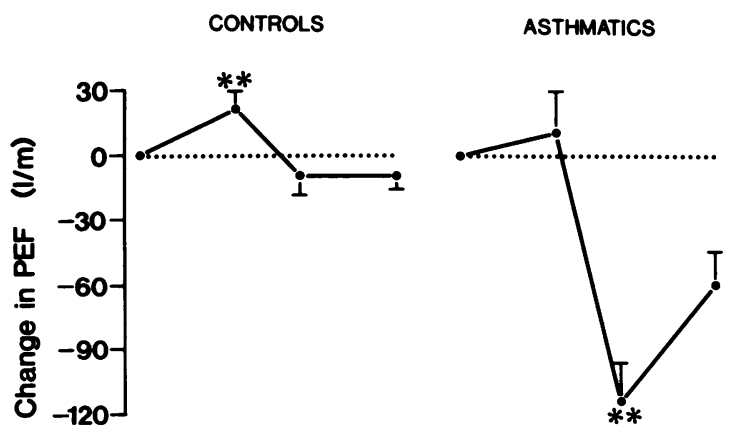

peak flow meter. At the same times blood samples were collected from an antecubital vein without venous stasis. A standard procedure regularly used in the laboratory was followed to minimise activation of platelets during collection and processing of blood. Venepuncture was carried out with minimal trauma and avoidance of suction in the syringe, a $19 \mathrm{G}$ Butterfly cannula being used. The first $2 \mathrm{ml}$ of blood was taken into a syringe and discarded. A second syringe was used to collect the next $5 \mathrm{ml}$ of blood, which was immediately and carefully decanted into an ice cooled test tube containing EDTA, theophylline, and prostaglandin $\mathrm{E}_{1}$ to inhibit platelet activation. Blood was mixed by gentle inversion of the tube and the samples were kept in melting ice for 30 minutes, before centrifugation at $2200 \mathrm{~g}$ and $4^{\circ} \mathrm{C}$ for 30 minutes. Aliquots of platelet poor plasma were removed from the middle layer of the supernatant plasma and stored at $-70^{\circ} \mathrm{C}$ until they were assayed. Plasma concentrations of platelet factor 4 and $\beta$ thromboglobulin were measured by radioimmunoassay with the kits supplied by Abbott Laboratories and Amersham International respectively. The normal ranges for our laboratory, obtained from 20 normal subjects aged 22-60 years, are 3.9 (SEM 0.3) and $31.7(2.1) \mathrm{ng} / \mathrm{ml}$ respectively. For platelet factor 4 the interassay coefficient of variation was $5 \%$ and the intra-assay coefficient of variation $8 \%$. For $\beta$ thromboglobulin the values were $10 \%$ and $8 \%$.

Differences between group values were assessed for

Fig 1 Changes in PEF and plasma concentrations of platelet factor 4 (PF4 $\square$ ) and $\beta$ thromboglobulin ( $\beta T G$; - - - ) during and after exercise in nine asthmatic patients and 12 normal controls (means with standard errors). The six minute exercise period is indicated by the hatched area. The significance of differences between resting and subsequent measurements (Wilcoxon test) is indicated by ${ }^{*}(p<0.05)$ and ${ }^{* *}(p<0.01)$.

exercised on only one occasion, preceded by administration of two puffs from a placebo inhaler. In the asthmatic subjects exercise was carried out on three occasions at the same time of day at weekly intervals. After baseline measurements salbutamol $200 \mu \mathrm{g}$, sodium cromoglycate $2 \mathrm{mg}$, or placebo were administered in the form of two puffs from a pressurised inhaler. The drugs were administered according to a random allocation by one observer (CEJ). All measurements of respiratory function and sampling of blood were carried out without knowledge of which drug a particular subject had received.

After a standard period of rest for 15 minutes, laboratory measurements were made 10 minutes before the exercise period. They were repeated immediately after exercise and 10 and 25 minutes after exercise. Peak expiratory flow was measured with a Wright's statistical significance with the Wilcoxon signed rank test and the two sample test for non-parametric data.

\section{Results}

Both asthmatic and control subjects exercised to a similar extent, with mean (SEM) increases in pulse rate of 69 (4) and 70 (5) beats per minute respectively. Exercise did not cause any distress to patients or normal subjects.

Exercise did not greatly affect PEF or platelet release proteins in the control subjects (fig 1). There was a small, transient rise in the values of all three measurements after exercise but this attained significance only for PEF ( $p<0.05$ ).

Individual results for platelet factor 4 and $\beta$ thromboglobulin in the asthmatic subjects before and after exercise are shown in the table. The individual rises in platelet factor 4 and $\beta$ thromboglobulin were significantly correlated $r=0.83(p<0.01)$.

In the asthmatic subjects PEF measurements showed typical exercise induced bronchoconstriction (fig 1). There was no significant change immediately after exercise but 10 minutes afterwards there was a significant mean fall of $1141 \mathrm{~min}^{-1}(p<0.01)$ below the resting value, and PEF had not returned to nor- 

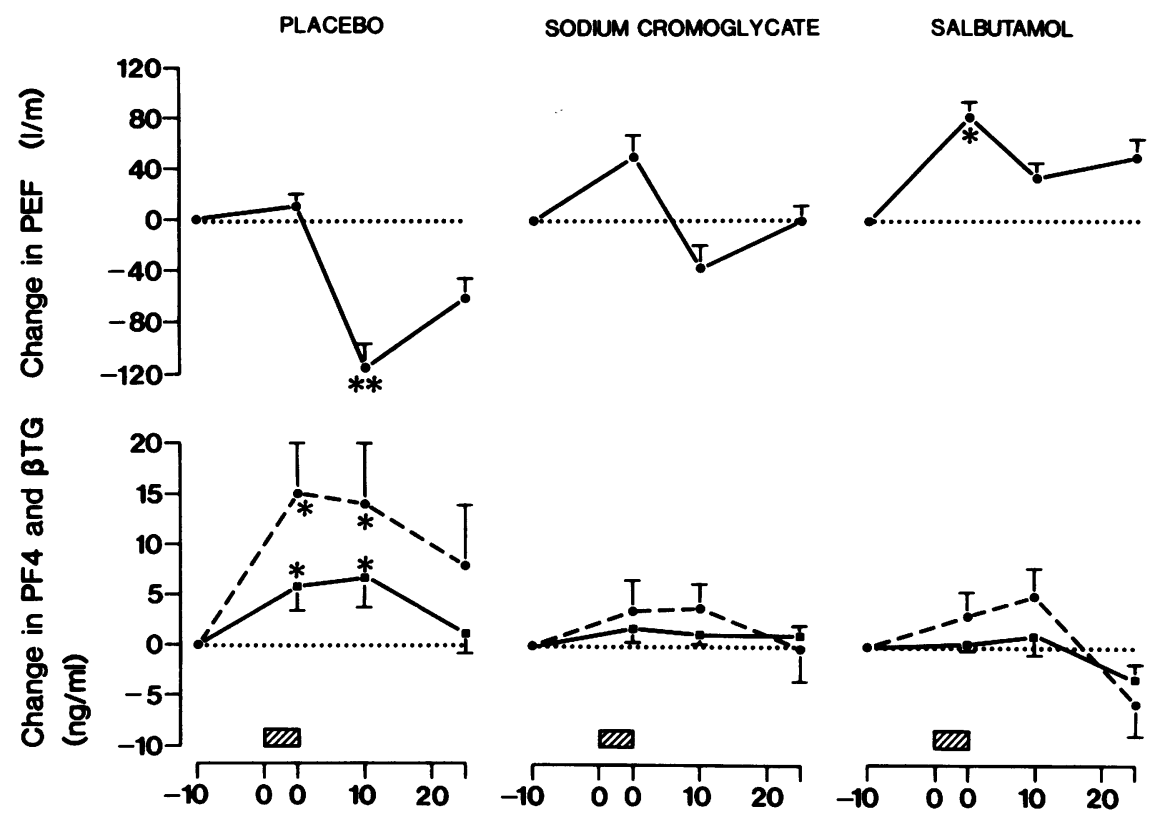

Time (min)
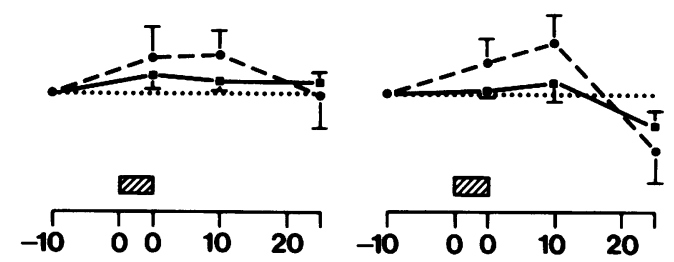

Time (min)

Time (min)

Fig 2 Effect of pretreatment with sodium cromoglycate or salbutamol on changes in peak expiratory flow (PEF) and plasma concentrations of platelet factor 4 (PF4 thromboglobulin ( $\beta T G ;---O)$ induced by a six minute period of exercise (hatched area) in nine asthmatic patients (means with standard errors). The significance of differences from resting values (Wilcoxon test) is indicated by $*(p<0.05)$ and ${ }^{* *}(p<0.01)$.

mal after 25 minutes. The changes in plasma concentrations of platelet factor 4 and $\beta$ thromboglobulin occurred more rapidly than those of PEF and returned to resting values more quickly (fig 1 ). By the end of the exercise period and 10 minutes after it there was a significant increase in plasma concentration of both platelet factor 4 and $\beta$ thromboglobulin ( $p<$ 0.05 ). Within 25 minutes of the end of the exercise both concentrations had fallen and were not significantly different from resting values. The indi- vidual increases in $\beta$ thromboglobulin and the fall i PEF were significantly correlated $(r=0.67, p \leqslant$ 0.05 ). For the individual increases in platelet factor $\frac{7}{4}$ and the fall in PEF $\mathrm{r}=0.61$, which just fails to reach significance.

Administration of salbutamol or sodium cro moglycate by aerosol to the asthmatic patients dimino ished the fall in PEF seen after exercise (fig 2 . Salbutamol in addition produced statisticall significant bronchodilation after exercise. The druge

Clinical details of asthmatic patients and the platelet factor 4 (PF4) and $\beta$ thromboglobulin (BTG) responses to exercise after placebo

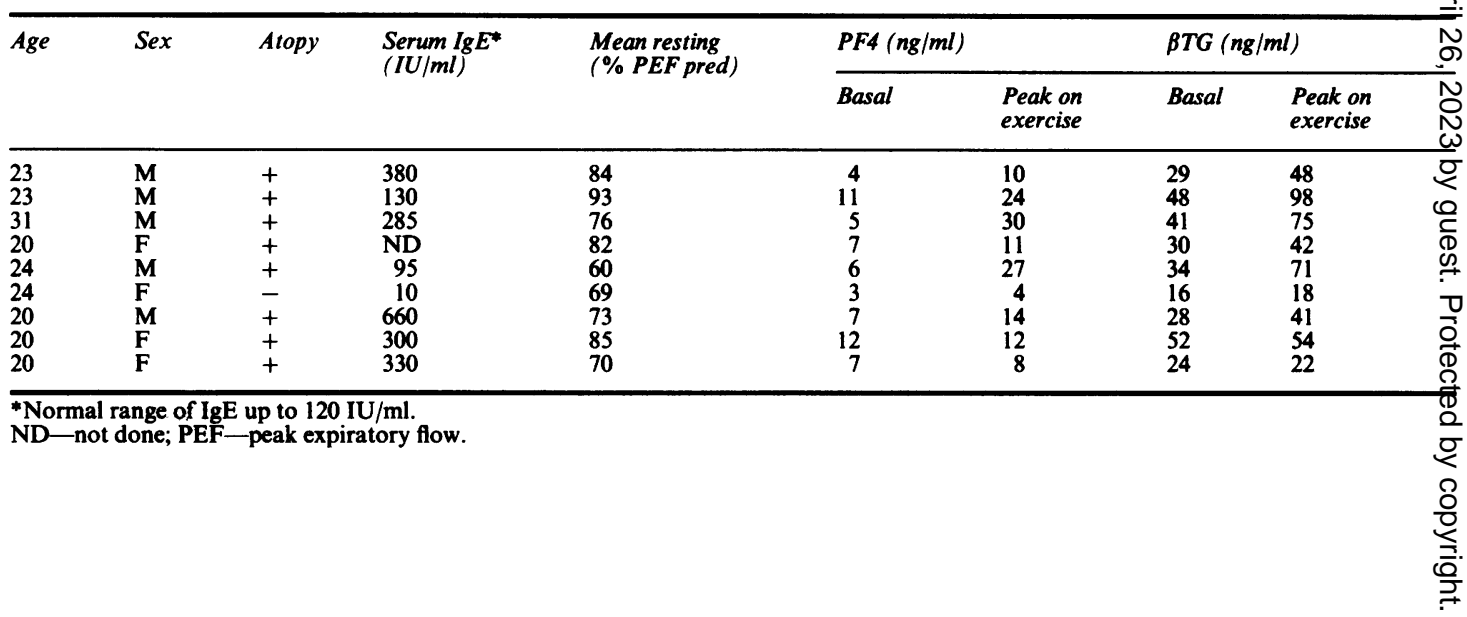


(fig 2) also prevented platelet activation after exercise in the asthmatic subjects $(\mathrm{p}<0.05)$; there was no significant difference in activity between the two drugs.

\section{Discussion}

The results indicate that platelet activation accompanies episodes of exercise induced asthma, with significant increases in plasma of the proteins platelet factor 4 and $\beta$ thromboglobulin. This response is not likely to be due to exercise alone, as there was an insignificant rise in the concentrations in nonasthmatic subjects, results that are in keeping with the findings of others. ${ }^{910}$ The association between bronchoconstriction and release of platelet proteins is strengthened by the observations that the rise accompanying exercise in patients given placebo was abolished by prior administration of salbutamol or of sodium cromoglycate. These experiments support the hypothesis that the release of platelet proteins indicates activity of mediators to which platelets are sensitive and is not merely an epiphenomenon associated with bronchoconstriction. Plasma platelet factor 4 and more noticeably $\beta$ thromboglobulin were considerably increased in asthmatic subjects at the end of the exercise period, before any reduction in PEF had occurred. This is consistent with previous reports that when bronchial smooth muscle is challenged directly by methacholine inhalation bronchoconstriction results without increase in plasma platelet factor $4 .^{1}$ It seems likely that the increase in plasma platelet factor 4 and $\beta$ thromboglobulin was derived from platelets. Although the former has been found in mast cells ${ }^{11}$ and binds reversibly to vascular endothelium, ${ }^{12} \beta$ thromboglobulin is platelet specific. ${ }^{13}$ Since the response of the two proteins is similar it is improbable that the material was derived from different sources.

The stimulus for platelet activation is not known, though platelet activating factor (PAF acether) might have this role. Platelet activating factor is a lipid derived from phosphorylcholine, which can be released from platelets themselves, IgE sensitised basophils, and other inflammatory cells. ${ }^{14}$ Experimental anaphylaxis in rabbits results in release of platelet activating factor and subsequent increase in plasma platelet factor 4 levels. ${ }^{15}$ Injection of platelet activating factor in guinea pigs produces platelet dependent bronchoconstriction ${ }^{16}$ and intradermal injection in man induces a rapid and delayed inflammatory reaction with a time sequence similar to that of clinical asthma. ${ }^{17}$ Inflammatory cells in the lungs also produce prostaglandins and leukotrienes, some of which could activate platlets at the same time as inducing bronchoconstriction and acting as mediators of hyperreactivity of the airways. ${ }^{1}$
It is generally agreed that chemical mediators play a part in antigen induced asthma, ${ }^{18-21}$ but the evidence for their role in exercise induced asthma has been much less convincing. ${ }^{2-24}$ The present study indicates that platelet activation occurs after exercise in asthmatic patients to much the same extent as after antigen challenge. ${ }^{2}$ The findings are consistent with the view that exercise induced asthma, at least in part, is produced by chemical mediators.

We are grateful to Miss KM Milner for secretarial assistance. We thank Allen and Hanburys Ltd and Fisons Pharmaceuticals for a grant towards the costs of laboratory reagents.

\section{References}

1 Goetzl EJ. Asthma: new mediators and old problems. $N$ Engl J Med 1984;311:252-3.

2 Knauer KA, Lichtenstein LM, Adkinson NF, Fish JE. Platelet activation during antigen induced airway reactions in asthmatic subjects. $N$ Engl J Med 1981; 304:1404-7.

3 Gresele P, Todisco T, Merante F, Nenci GG. Platelet activation and allergic asthma [letter]. $N$ Engl $J$ Med 1982;306:549.

4 Deal EC, Wasserman SI, Soter NA, Ingram RH, McFadden ER. Evaluation of role played by mediators of immediate hypersensitivity in exercise-induced asthma. $J$ Clin Invest 1980;65:659-65.

5 Weiler-Ravell D, Godfrey S. Do exercise- and antigeninduced asthma utilise the same pathways? Antigen provocation in patients rendered refractory to exerciseinduced asthma. J Allergy Clin Immunol 1981;67:391-7.

6 Lee TH, Assouf BK, Kay AB. The link between exercise, respiratory heat exchange, and the mast cell in bronchial asthma. Lancet $1983 ; \mathrm{i}: 520-2$.

7 Howarth PH, Holgate ST. Exercise, asthma and mast cells [letter]. Lancet 1983;i:822.

8 Godfrey S, Konig P. Inhibition of exercise-induced asthma by different pharmacological pathways. Thorax 1976;31:137-44.

9 Green LH, Seroppian E, Handin RI. Platelet activation during exericse-induced myocardial ischaemia. $N$ Engl $J$ Med 1980;302:193-7.

10 Mathis PC, Wohl H, Wallach SR, Engler RL. Lack of release of platelet factor 4 during exercise-induced myocardial ischaemia. $N$ Engl J Med 1981;304:1275-8.

11 McLaren KM, Holloway L, Pepper DS. Human platelet factor 4 and tissue mast cells. Thromb Res 1980;19:293-7.

12 Busch C, Dawes J, Pepper DS, Wasteson A. Binding of platelet factor 4 to cultured human endothelial cells [abstract]. Thromb Haemostas 1979;42:43, 89.

13 Zahavi J, Kakkar VV. $\beta$-Thromboglobulin-a specific marker of in-vivo platelet release reaction. Thromb Haemostas 1980;44:23-30.

14 Morley J, Sanjar S, Page CP. The platelet in asthma. Lancet 1984;ii:1142-4.

15 McManus LM, Morley CA, Levine SP, Pinckard RN. Platelet activating factor (PAF) induced release of platelet factor 4 (PF4) in vitro and during IgE anaphylaxis in the rabbit. $J$ Immunol 1979;123:2835-41. 
16 Vargaftig BB, Lefort J, Chignard M, Benveniste J. Platelet-activating factor induces platelet-dependent bronchoconstriction unrelated to the formation of prostaglandin derivatives. Eur J Pharmacol 1980;65:185-92.

17 Basran GS, Morley J, Paul W, Turner-Warwick M. Evidence in man of synergistic interaction between putative mediators of acute inflammation and asthma. Lancet 1982;i:935-7.

18 Brown MJ, Ind PW, Causon R, Lee TH. A novel doubleisotope technique for the enzymatic assay of plasma histamine; application to estimation of mast cell activation assessed by antigen challenge in asthmatics. $J$ Allergy Clin Immunol 1982;69:20-4.

19 Atkins PC, Norman ME, Zweiman B. Antigen-induced neutrophil chemotactic activity in man. Correlation with bronchospasm and inhibition by disodium cromoglycate. J Allergy Clin Immunol 1978;62:149-55.

20 Nagy L, Lee TH, Kay AB. Neutrophil chemotactic activ- ity in antigen-induced late asthmatic reactions. $N$ Engl Med 1982;306:497-501.

21 Green K, Hedquist P, Svanborg N. Increased plasma levels of 15-keto-13,14-dihydro-prostaglandin $F_{2}$ after allergen provoked asthma in man. Lancet 1974; ii:1419-21.

22 Anderson SD, Pojer R, Smith ID, Temple D. Exercise- $\frac{\overline{\bar{S}}}{\overline{7}}$ related changes in plasma levels of 15-keto-13,14-dihydro-prostaglandin $F_{2}$ alpha and noradrenaline in asthmatic and normal subjects. Scand 50 Respir Dis 1976;57:41-8.

23 Morgan DJ, Phillips MJ, Moodley I, Elliott EV, Davies RJ. Histamine, neutrophil chemotactic factor and circu- $\vec{\omega}$ lating basophil levels following exercise in asthmaticso and control subjects. Clin Allergy 1982;12, suppl:29-37. $\vec{F}$

24 Ind PW, Barnes PJ, Brown MJ, Causon R, Dollery CT. Measurement of plasma histamine in asthma. Clin Al- $=$ lergy 1983;13:61-7. 